\title{
Factors Affecting Community Pharmacist's Knowledge About Chronic Obstructive Pulmonary Disease (COPD) Management in China: A Cross-Sectional Survey Study
}

This article was published in the following Dove Press journal:

International Journal of Chronic Obstructive Pulmonary Disease

\author{
Yuqi $\mathrm{Hu}{ }^{\mathrm{l}, 2, *}$ \\ Dongning Yao iD ${ }^{1,2, *}$ \\ Hao Hu (iD) ${ }^{1,2}$ \\ Carolina Oi Lam Ung (D) \\ 'State Key Laboratory of Quality \\ Research in Chinese Medicine, Institute \\ of Chinese Medical Sciences, University \\ of Macau, Macao People's Republic of \\ China; ${ }^{2}$ National Licensed Pharmacist \\ Development Research Center, China \\ Pharmaceutical University, Nanjing City, \\ Jiangsu Province 210009, People's \\ Republic of China \\ *These authors contributed equally to \\ this work
}

\begin{abstract}
Purpose: Chronic obstructive pulmonary disease (COPD) has become a significant risk factor that threatens public health. Many studies have confirmed that the professional services for COPD patients by community pharmacists can improve comprehensive benefits. However, there's less research investigating the factors affecting community pharmacists' knowledge about COPD management. Therefore, this study aimed to investigate the knowledge of COPD among community pharmacists in China and analyze the factors affecting community pharmacist's knowledge about COPD management.
\end{abstract}

Methods: This study employed a face-to-face, self-administered questionnaire survey targeting community pharmacists from three cities (Nanjing, Zhuhai, Qingyang) in China. Descriptive statistics, $t$-test and one-way ANOVA were used for data analysis.

Results: Out of the 794 pharmacists surveyed, 177 (22.3\%) were completed and valid. The majority $(91.0 \%)$ of participants had a positive attitude they were responsible for assisting patients to control the disease progression. Among 12 knowledge-related survey questions, only 34 (19.2\%) pharmacists answered more than half of them correctly, showing that overall knowledge level of participants was generally low. The overall knowledge level was significantly $(P<0.05)$ associated with higher academic education, on-the-job training, and pharmacies selling drugs for treating COPD. Regarding medical knowledge, participants got higher accuracy rates at some questions as the symptoms of COPD and identifying the main causative factors but were weak in disease characteristics and guidelines for disease diagnosis. As for medication, participants had a certain understanding of different drugs for COPD and their adverse reactions. For non-drug treatment, participants could not entirely choose the best non-drug treatment for patients, while most of them recognize the importance of pulmonary rehabilitation.

Conclusion: This research indicated that community pharmacists in China lacked sufficient knowledge about COPD management. It is necessary to improve university education, strengthen on-the-job training, adjust the social insurance system, and develop service guidelines for licensed pharmacists to support their professional services for COPD patients. Keywords: community pharmacist, chronic obstructive pulmonary disease, community pharmacy, knowledge, chronic disease management, survey

\section{Introduction}

Chronic obstructive pulmonary disease (COPD) is a chronic inflammatory lung disease that is characterized by an irreversible decline in lung function and can cause progressive functional disability and a significant impact on the quality of
Lam Ung

State Key Laboratory of Quality Research in Chinese Medicine, Institute of Chinese Medical Sciences, University of Macau,

Taipa N22-2057, Macao

Tel +85388228538

Email haohu@um.edu.mo;

carolinaung@um.edu.mo
International Journal of Chronic Obstructive Pulmonary Disease 2020:|5 3|7|-3|8|

3171

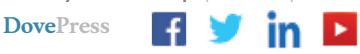

http://doi.org/10.214 
life. ${ }^{1}$ Worldwide, a total of 65 million people worldwide suffer from COPD with moderate to severe severity, and more than 3 million people die from COPD each year, representing an estimated $6 \%$ of all deaths. ${ }^{2}$ COPD is also associated with significant economic burden mainly contributed by hospitalizations for exacerbations which account for 18 million USD in direct costs annually just in the United States and burden the healthcare budgets with direct costs of around 47.3 billion EUR for the European Union. ${ }^{3}$ Despite the high prevalence, morbidity, mortality, and costs, COPD receives little attention in comparison with other major causes of global morbidity and mortality. ${ }^{3}$

The majority of COPD cases are primarily the results of preventable causes such as tobacco smoking and household air pollution. ${ }^{4}$ The under-diagnosis of COPD is an essential aspect of COPD burden with diagnosis is often made only when the condition has become advanced. ${ }^{5}$

Some of the common comorbidities that affect the prognosis of COPD include cardiovascular diseases, chronic renal failure, diabetes mellitus, and other metabolic syndromes, and depression and anxiety, etc. ${ }^{6-8}$ Challenges in COPD management are also evident with the high prevalence of hospitalization due to exacerbations triggered either by infections (viral or bacterial) ${ }^{9}$ or noninfectious causes (such as air pollution, meteorological effect). ${ }^{10,11}$ For many patients with COPD, a combination of high symptom load, compromised physical activities, non-compliance, and deteriorating quality of life means they are in great need for a high level of continuous support from health services. ${ }^{12}$

To address the unmet burden of COPD, the value of community pharmacists as part of an integrative approach to providing care to patients with COPD at the community level has been widely explored. ${ }^{13}$ A literature review has identified community pharmacists' supporting role regarding COPD management in four areas at least: primary prevention, early detection/case finding, management, and ongoing support and review/follow-up. ${ }^{13}$ It has been suggested that community pharmacists are well positioned to play a key role in raising disease awareness, ${ }^{14}$ encouraging and supporting smoking cessation, ${ }^{15}$ educating about lifestyle options and disease management, ${ }^{16}$ performing COPD screening, ${ }^{17}$ referring high-risk patients to doctors, ${ }^{18}$ supporting self-management and encouraging flu vaccination, ${ }^{19}$ reviewing patients' pharmacotherapy and monitoring patient's technique and adherence, ${ }^{20}$ and supporting management plan that minimize exacerbation. ${ }^{21}$ In 2019, the International Pharmaceutical Federation (FIP) outlined the benefits of pharmacists in the therapeutic management of patients with COPD and other chronic diseases supported with evidence collected around the world. ${ }^{22}$

Pharmacist-led interventions in COPD management require these medicine experts to expand their expertise beyond pharmacotherapy towards, eg, smoking cessation services, flu vaccination, and overall disease management. Among all contextual factors, the COPD knowledge possessed by a community pharmacist played a decisive role in the implementation of professional services. However, little is known about community pharmacists' knowledge and competence related to COPD. Research is needed to identify any gaps in pharmacists' competence and to determine needs for development, in order to improve COPD management practices by community pharmacists. The need for research in this area is global as community pharmacists in any country should be competent and knowledgeable about the care needed by COPD patients and should base their professional practice on evidencebased medicine.

Thus, this study aimed to analyze the level of such knowledge, as well as the factors associated with gaining that knowledge among Chinese community pharmacists. China has the world's largest group of patients with COPD. The findings from this study are expected to contribute to improve managing COPD by community pharmacists in China and provide references for enhancing COPD knowledge of community pharmacists internationally.

\section{Method}

\section{Research Design}

This study applied a cross-sectional survey with written questionnaires to evaluate community pharmacists' knowledge about COPD management and related impact factors.

\section{Sampling}

From July to August 2019, we conducted multi-center surveys in China and selected three cities, Nanjing City, Qingyang City, and Zhuhai City, as the target survey areas for this study. These cities are located in eastern, southern, and northwestern China, which represent different social and economic levels (see Table S1 for more detailed background information about the selected cities). 
Considering the difference in population and administrative divisions of the three cities, this study chose the administrative district with the highest population density in the city. Finally, we selected the Gulou District for Nanjing City, Xifeng District for Qingyang City, and Xiangzhou District for Zhuhai City.

For each administration district, we applied an online map to identify the community pharmacies. Using the online Gaode map (https://www.amap.com/), we searched "Gulou District, Nanjing City" + "pharmacy", "Xifeng District, Qingyang City" + "pharmacy", and "Xiangzhou District, Zhuhai City" + "pharmacy" as key terms for searching all community pharmacies in the selected administration districts, and the retrieved records were 210, 280, and 810, respectively (accessed on 21 July 2019).

Two researchers (YH \& DY) examined the search results one by one to eliminate the community pharmacies: (1) unclear addresses; (2) incorrect search results; (3) specializing in herbal medicine; and (4) in rural areas with addresses too remote to investigate. Finally, the actual number of community pharmacies included in the study in each city was 190, 161, and 443, respectively. All of the community pharmacies in sample districts were visited in person by the researchers. In each community pharmacy, we invited one licensed pharmacist to complete the questionnaire. There are two types of pharmacist license in China: Traditional Chinese Medicines or TCMs pharmacist license, and Western Medicine license. The licensed pharmacists at the community pharmacy may hold one or both of the licenses.

\section{Data Collection}

Data collection was implemented through on-site survey with a self-filled hard copy of the questionnaire. From July 20 to August 30, 2019, five investigators conducted the fieldwork of questionnaires in the selected cities. All the investigators were postgraduate students at the University of Macau who received systematic training before the survey. The content of training includes the research background, purpose, significance, and other research contents of the survey. Each question in the questionnaire was explained in detail to the investigators during the training so that they could address any possible queries from the participants about the interpretation of the questions in a standardized manner.

For fieldwork, the investigators found the selected target community pharmacies based on the address identified above. After arriving at the community pharmacy, they looked for a licensed pharmacist on duty, showed their student ID card and introduction letter, explained to the pharmacist about the purpose of the investigation, and then asked if pharmacists would like to participate in the survey project. After receiving the affirmative reply from the pharmacists, they provided an informed consent form to the pharmacists. Then, the pharmacists finished the hard copy of the questionnaire without any interference unless the pharmacist had questions about the questionnaire and would like to ask for clarification from the investigator. If the pharmacist completed the questionnaire, the survey was recorded as a successful one. For the following cases, it was recorded as a missed pharmacy visit: absence of licensed pharmacists; pharmacist refusal to participate; pharmacy closed; pharmacy address mismatch; and pharmacy located in the hospitals.

\section{Questionnaire Development}

The questionnaire was developed in consultation with the literature review finished before. The questionnaire was initially developed in English, then translated into Chinese. Two members (CU \& DY) who are proficient in English and Chinese bilinguals evaluated the accuracy of the language words in the questionnaire and proposed their amendments, in order to ensure the accuracy of the questionnaire translation. After the design of the questionnaire was completed, two pharmacists with long-term practicing experience in COPD were asked to propose further amendments and adjustments based on their professional perspective of the practitioners. Then, the researcher obtained a complete version of the questionnaire with reference to the opinions of pharmacists.

The final vision questionnaire is separated into two sections. In the first part, the demographic information was queried, including personal information, information about the practice, and information about the practice process and COPD. The second part was used for investigating pharmacist's knowledge of COPD management (see Survey Questionnaire). A total of 12 questions which were sourced from previous qualification exams for licensed pharmacists and mock test question were surveyed, covering nine themes: cause of COPD, disease characteristics, symptoms, diagnosis, guidelines, medications, adverse drug reactions, non-drug treatments, and pulmonary rehabilitation. Two questions are multiple-choice questions, and the remaining 10 are true or false questions presented in the questionnaire. Each question gave the pharmacist 
the option of "unclear" to withdraw from the question, if the pharmacist indicates that he was not sure of the correct answer to this question.

\section{Data Analysis}

After the questionnaire collection, researchers checked the completeness of the questionnaire first, removed the questionnaires that are not entirely completed, or have apparent answer errors. The collected questionnaire data were then entered into a computer using the Statistical Package for Social Sciences (SPSS 24.0 for Windows Version). Descriptive statistics was performed on demographic information. The total number of COPD-related knowledge questions correctly answered by each pharmacist was counted to reflect the participants' knowledge about COPD management. Independent sample $t$-test was used for testing the demographic information and the pharmacist's knowledge of the disease if the demographic information is a binary classification and one-way ANOVA for the multiple classifications. In this study, $P<0.05$ was considered statistically significant.

\section{Ethics Approval}

This study was approved by the Ethics Committee of the China Pharmaceutical University under the approval number of "ndrplc201901". This study complied with the Declaration of Helsinki. Informed consent is obtained from the participants.

\section{Results}

\section{Background Information of Participants}

Of the 794 community pharmacies targeted, 177 participant community pharmacists completed the questionnaire (response rate $=22.3 \%$ ). The valid questionnaires in Nanjing City, Qingyang City, and Zhuhai City were 59 (response rate $=31.1 \%$ ), 36 (response rate $=22.3 \%$ ), and 82 (response rate $=18.5 \%$ ) respectively. The majority of the respondents $(77.4 \%)$ were female. There were more TCMs-Licensed pharmacists than western medicinelicensed pharmacist. Eight participants obtained both types of pharmacist licenses. The majority of participants $(80.2 \%)$ worked at chain pharmacies.

Two-thirds $(66.7 \%)$ of the participants reported that their pharmacy sold medicines for the treatment of COPD. Only $41.2 \%$ participants reported any previous training on COPD management during school education. Less than half of them (45.8\%) received training on COPD management during employment. However, 91.0\% participants thought that they had a responsibility to participate in chronic disease management of COPD (see Table 1).

\section{Overall Knowledge Level and Its Affecting Factors}

Among all the participants, the overall accuracy rate of participants to COPD knowledge-related questions was relatively low. Of the 12 questions, only 34 (19.2\%) of pharmacists answered more than 6 questions correctly (see Figure 1).

Statistical analysis showed that the difference in the level of COPD-related knowledge was associated with participants' highest level of education, participants with a bachelor's degree answered more questions correctly than others $(P<0.05)$. Also, pharmacies selling drugs for treating COPD and pharmacists who received COPDrelated training during their employment are associated with more correct answers $(P<0.05)$. Other background factors of participants were not significantly associated with participants' correct answers to these questions (see Table 2).

\section{Knowledge Comprehension in Different Topic}

Participants showed varied accuracy in different aspects of COPD-related knowledge. For medical background information, almost all participants $(96.6 \%)$ were aware of the symptoms of COPD. However, only $4.0 \%$ participants could entirely choose all the causes of COPD. Besides, the participants obtained a low accuracy rate in disease characteristics (33.3\%), disease diagnosis (13.0\%), and the choice of COPD guidelines $(27.1 \%)$, indicating that the participants were short of medical background knowledge.

In terms of medication, $79.7 \%$ of participants clearly understood the adverse drug reactions of some common drugs used to treat COPD; $74.6 \%$ answered the medication of short-acting bronchodilators correctly; and $70.1 \%$ of participants correctly answered the medication of shortterm oral glucocorticoids. Nevertheless, the participants showed a low accuracy rate in question about inhaled drugs $(9.6 \%)$, inhaled glucocorticoids $(25.4 \%)$.

Only $6.8 \%$ of participants could answer all the questions about non-drug treatments. Also, $87.6 \%$ of participants correctly answer the question about the application of pulmonary rehabilitation treatment in COPD (see Table 3). 
Table I Background Information of Participants (N= I77)

\begin{tabular}{|c|c|}
\hline Demographic Information & $\begin{array}{l}\text { Number of } \\
\text { Respondents (\%) }\end{array}$ \\
\hline \multicolumn{2}{|l|}{ Gender } \\
\hline Male & $40(22.6 \%)$ \\
\hline Female & $137(77.4 \%)$ \\
\hline \multicolumn{2}{|l|}{ Age } \\
\hline $20-30$ & $34(19.2 \%)$ \\
\hline $31-40$ & $84(47.5 \%)$ \\
\hline $4 I-50$ & $52(29.4 \%)$ \\
\hline $5 I-60$ & $4(2.3 \%)$ \\
\hline 61 or above & $3(1.7 \%)$ \\
\hline \multicolumn{2}{|l|}{ City } \\
\hline Nanjing & $59(33.3 \%)$ \\
\hline Qingyang & $36(20.3 \%)$ \\
\hline Zhuhai & $82(46.3 \%)$ \\
\hline \multicolumn{2}{|l|}{ Highest qualification } \\
\hline Specialized secondary school & $31(17.5 \%)$ \\
\hline High school & $4(2.3 \%)$ \\
\hline Diploma & $99(55.9 \%)$ \\
\hline Undergraduate & $43(24.3 \%)$ \\
\hline Postgraduate & $0(0.0 \%)$ \\
\hline Ph. D & $0(0.0 \%)$ \\
\hline \multicolumn{2}{|l|}{ Years of practice as pharmacist } \\
\hline$<1$ year & $2(1.1 \%)$ \\
\hline $1-5$ & $23(13.0 \%)$ \\
\hline $6-10$ & $37(20.9 \%)$ \\
\hline $11-15$ & $55(31.1 \%)$ \\
\hline $16-20$ & $4 I(23.2 \%)$ \\
\hline 21 or above & $19(10.7 \%)$ \\
\hline \multicolumn{2}{|l|}{ Workload per week } \\
\hline $1-16$ hours & $7(4.0 \%)$ \\
\hline $17-32$ hours & $2(1.1 \%)$ \\
\hline $33-40$ hours & $17(9.6 \%)$ \\
\hline $4 I-48$ hours & $81(45.8 \%)$ \\
\hline 49 hours or above & $70(39.5 \%)$ \\
\hline \multicolumn{2}{|l|}{ Type of pharmacy } \\
\hline Chain pharmacy & $142(80.2 \%)$ \\
\hline Monomer pharmacy & $35(19.8 \%)$ \\
\hline \multicolumn{2}{|l|}{ Pharmacist category } \\
\hline TCMs-Licensed pharmacist & $100(56.5 \%)$ \\
\hline Western Medicine-Licensed pharmacist & $69(39.0 \%)$ \\
\hline Both obtained two licenses & $8(4.5 \%)$ \\
\hline \multicolumn{2}{|l|}{ Does pharmacy sell drugs for COPD } \\
\hline Yes & $118(66.7 \%)$ \\
\hline No/Unclear & $59(33.3 \%)$ \\
\hline \multicolumn{2}{|l|}{ Received training on COPD during school } \\
\hline Yes & $73(41.2 \%)$ \\
\hline No/Unclear & $104(58.8 \%)$ \\
\hline
\end{tabular}

(Continued)
Table I (Continued).

\begin{tabular}{|l|l|}
\hline Demographic Information & $\begin{array}{l}\text { Number of } \\
\text { Respondents (\%) }\end{array}$ \\
\hline $\begin{array}{l}\text { Received training on COPD during } \\
\text { employment }\end{array}$ & \\
Yes & $81(45.8 \%)$ \\
No/Unclear & $96(54.2 \%)$ \\
\hline Attitude towards pharmacists participating in & \\
disease management of COPD & \\
Strongly agree/Agree & $161(91.0 \%)$ \\
Unclear & $12(6.8 \%)$ \\
Strongly disagree/Disagree & $4(2.3 \%)$ \\
\hline
\end{tabular}

\section{Discussion}

In this study, community pharmacists in China were assessed about their perception of their role expansion and their basic knowledge in COPD. While many community pharmacists were positive about stepping up their professional duties in COPD management, the study revealed that their overall knowledge about COPD and disease management was insufficient. Community pharmacists who had higher education levels or received COPDrelated continuing professional development (CPD) scored higher in the level of COPD knowledge, indicating a need for additional education and training before and during practice. While most community pharmacists scored higher in the knowledge about COPD symptoms, the importance of pulmonary rehabilitation and pharmacotherapy, the knowledge scores in etiology, diagnosis, and nonpharmacotherapy lagged. The weaknesses identified could be used to inform the design of education/training programs that can better address the knowledge gaps.

While $91 \%$ of community pharmacists in this study agreed or strongly agreed that they should become part of an integrated approach to COPD management, fewer than $20 \%$ of the community pharmacists in this study were able to respond to at least half of the assessment questions correctly. Pharmacists' lack of COPD knowledge had been repeatedly reported in previous studies based on the selfreported level of understanding about the disease. A crosssectional survey in the United Kingdom showed that 81.1\% of 1046 community pharmacists considered that they had insufficient knowledge of COPD, and improvement in this area was warranted. ${ }^{15}$ A survey of 80 community pharmacists in Belgium revealed that $18 \%$ of pharmacists stated that they had insufficient knowledge about COPD and therefore hindered themselves from providing professional 


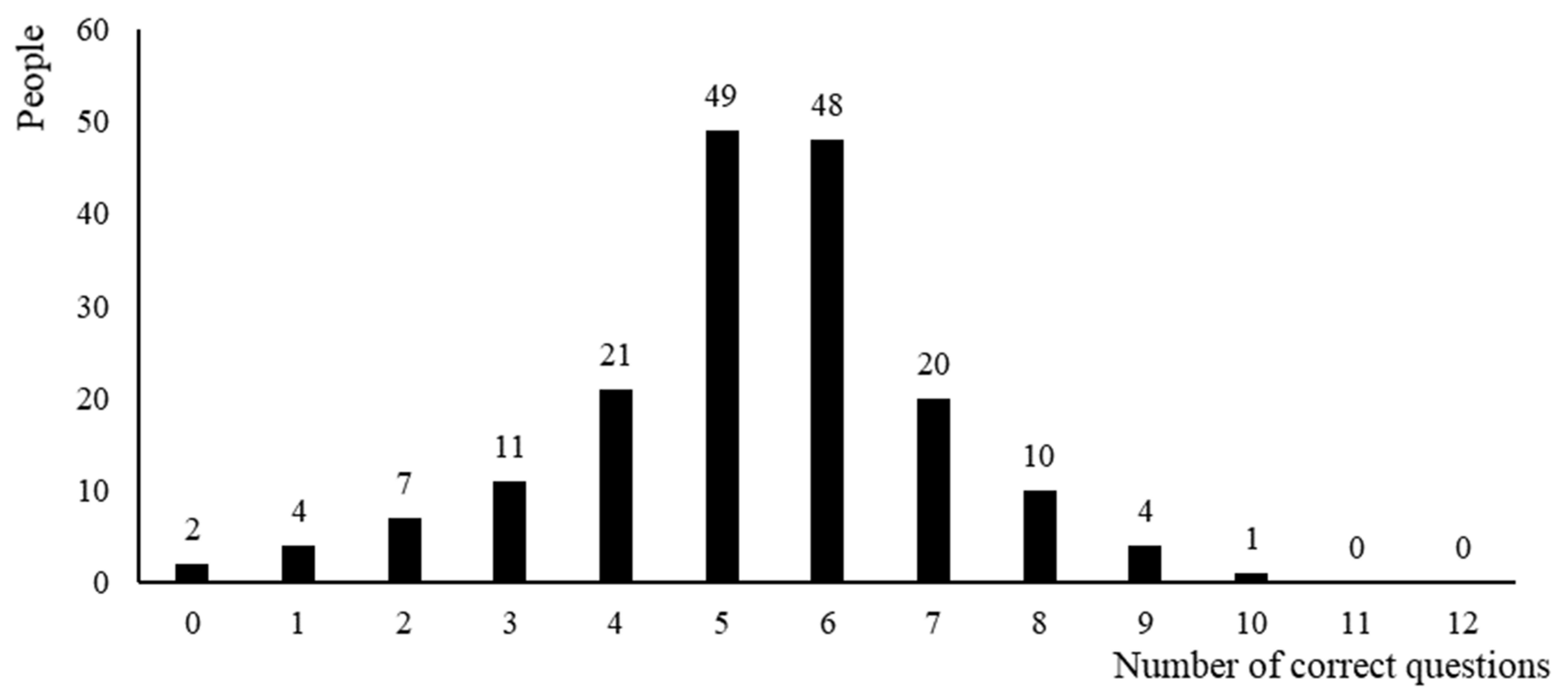

Figure I Number of questions correctly answered by participants.

services to COPD patients. ${ }^{23}$ Another survey in Finland pointed out that community pharmacists usually overestimated their professional skills than their prescribed operations from guideline standards. ${ }^{24}$ This current study took a more objective approach by using assessment questions, and the results verified the concerns over pharmacists' lack of knowledge in COPD by analyzing their responses to assessment questions.

The situation in China regarding pharmacists' competence may have been complicated by the qualification system in place. ${ }^{25}$ By law, pharmaceutical professionals who obtain a passing grade at the national pharmacist licensing exam can obtain a Licensed Pharmacist Certificate, get registered and be approved to work at community pharmacy as licensed pharmacists. The minimum qualification to apply for the licensed pharmacist qualification examination can be just a secondary technical school diploma and a major in pharmacy or related disciplines in addition to certain years of working experiences. The lack of standardization of basic academic qualification might have contributed to various levels of professional competence especially when it comes to direct patient care as observed in this study. It is anticipated that the study results will contribute to informing not only the strategic actions for improving COPD management at community level but also the qualification and education systems of pharmacists in the country.

Nevertheless, as reported by the FIP, in nearly one out of five surveyed countries, pharmacists do not receive formal training in pharmaceutical care specifically focused on COPD. ${ }^{22}$ This highlights a significant area of concern in terms of workforce development for pharmacists. The issue of primary education and training in patient-centered care is particularly complicated in China. As of February 2020, there were 522,461 licensed pharmacists or 3.7 pharmacists per 10,000 population in China, of which $90 \%$ worked in retail pharmacies. ${ }^{26}$ The density of pharmacists (total number per 10,000 population) was much lower than that in Australia (12.59), Canada (11.74), the United States (9.19), and other developed countries. ${ }^{27}$ Traditionally, the main objective of the pharmacy education program was to produce pharmacy graduates qualified for handling chemicals effectively and safely in compliance with the laws and regulations and formulating preparing pharmaceutical products. As a result, the competence of the pharmacist workforce skewed towards drug products rather than patientcentered care. This was until the 1990s when the concept of pharmaceutical care was introduced into the practice of pharmacy which led to community pharmacists' involvement in more professional activities. ${ }^{28}$ To meet the demand for clinical knowledge, clinical pharmacy programs were established in China in 1989 but became more developed only after $2006 .{ }^{28}$ However, the shift of education focus from product-centered to patient-centered is yet to keep pace with the changing and increasing demand for patient care at the community level. To remove the gaps between the knowledge deficit and 
Table 2 Number of Correct Answers Among Possible Affecting Factors

\begin{tabular}{|c|c|c|}
\hline & $\begin{array}{l}\text { Number of Correct } \\
\text { Question Answer }\end{array}$ & $P$ value \\
\hline \multicolumn{3}{|l|}{ Gender } \\
\hline Male & 5.25 & 0.922 \\
\hline Female & 5.29 & \\
\hline \multicolumn{3}{|l|}{ Age } \\
\hline $20-30$ & 4.97 & 0.142 \\
\hline $31-40$ & 5.29 & \\
\hline $4 I-50$ & 5.50 & \\
\hline $51-60$ & 6.25 & \\
\hline 61 or above & 3.33 & \\
\hline \multicolumn{3}{|l|}{ City } \\
\hline Nanjing & 5.32 & 0.963 \\
\hline Qingyang & 5.22 & \\
\hline Zhuhai & 5.27 & \\
\hline \multicolumn{3}{|l|}{ Highest qualification } \\
\hline Specialized secondary school & 5.32 & 0.031 \\
\hline High school & 2.75 & \\
\hline Diploma & 5.29 & \\
\hline Undergraduate & 5.44 & \\
\hline Postgraduate & 0 & \\
\hline Ph. D & 0 & \\
\hline \multicolumn{3}{|l|}{ Years of practice as pharmacist } \\
\hline$<1$ year & 4.50 & 0.825 \\
\hline $1-5$ & 5.48 & \\
\hline $6-10$ & 5.16 & \\
\hline $11-15$ & 5.13 & \\
\hline $16-20$ & 5.54 & \\
\hline 21 or above & 5.21 & \\
\hline \multicolumn{3}{|l|}{ Workload per week } \\
\hline $1-16$ hours & 6.27 & 0.182 \\
\hline $17-32$ hours & 4.00 & \\
\hline $33-40$ hours & 4.65 & \\
\hline $4 I-48$ hours & 5.22 & \\
\hline 49 hours or above & 5.43 & \\
\hline \multicolumn{3}{|l|}{ Type of pharmacy } \\
\hline Chain pharmacy & 5.31 & 0.140 \\
\hline Monomer pharmacy & 5.27 & \\
\hline \multicolumn{3}{|l|}{ Pharmacist category } \\
\hline TCMs-Licensed pharmacist & 5.02 & 0.173 \\
\hline $\begin{array}{l}\text { Western Medicine-Licensed } \\
\text { pharmacist }\end{array}$ & 5.57 & \\
\hline Both obtained two licenses & 6.00 & \\
\hline \multicolumn{3}{|l|}{$\begin{array}{l}\text { Does the pharmacy sell drugs for } \\
\text { COPD }\end{array}$} \\
\hline Yes & 5.52 & 0.007 \\
\hline No/Unclear & 4.80 & \\
\hline
\end{tabular}

(Continued)
Table 2 (Continued).

\begin{tabular}{|l|l|l|}
\hline & $\begin{array}{l}\text { Number of Correct } \\
\text { Question Answer }\end{array}$ & P value \\
\hline $\begin{array}{l}\text { Received training on COPD during } \\
\text { school } \\
\text { Yes }\end{array}$ & 5.53 & \\
No/Unclear & 5.10 & 0.105 \\
\hline $\begin{array}{l}\text { Received training on COPD during } \\
\text { employment }\end{array}$ & & \\
Yes & 5.72 & 0.002 \\
No/Unclear & 4.91 & \\
\hline $\begin{array}{l}\text { Attitude towards pharmacists } \\
\text { participating in disease management } \\
\text { of COPD }\end{array}$ & & 0.492 \\
Strongly agree/Agree & 5.30 & \\
Unclear & 5.25 & \\
Strongly disagree/Disagree & 4.25 & \\
\hline
\end{tabular}

expected practice standards, careful review and thorough modernization of pharmacy education program and curriculum are urgently needed to prepare community pharmacists for the new and emerging roles.

The qualification system for licensed pharmacists that set the minimum qualification required to sit for the national pharmacist licensing examination at secondary school level further risked the variations in the knowledge gaps of the pharmacist workforce in China. ${ }^{29}$ As shown in this study, participants who had bachelor degree showed a higher grasp of COPD knowledge compared to those who only received diploma education or below. To further illustrate the differences across the education programs, we compared the diploma education program with the bachelor education program offered by the China Pharmaceutical University (one of the first university in China allowed to offer bachelor, master, and Ph.D. degree in clinical pharmacy). ${ }^{30}$ Besides the different course durations (4 years for the bachelor degree, and 3 years for the diploma program), the teaching content varied to a great degree (see Table S2). The prime focus of the diploma program rested on pharmaceutical technology, and clinical practice was only taught in the bachelor's degree. Comparatively, the design of the bachelor program can better prepare pharmacists with relevant clinical knowledge to provide direct-to-patient care. The fundamental paradigm shift in reinforcing pharmacists' capacity in improving their professional care for 
Table 3 Answers to COPD-Related Knowledge Questions

\begin{tabular}{|c|c|c|}
\hline Question Topic & Question Statement & $\begin{array}{l}\text { Number of Correct } \\
\text { Answers (\%) }\end{array}$ \\
\hline $\begin{array}{l}\text { Risk factors (correct answer: } \\
\text { a b c e) }\end{array}$ & $\begin{array}{l}\text { The risk factors for COPD are: } \\
\text { a. Smoking } \\
\text { b. Pulmonary infections } \\
\text { c. Air pollution and dust } \\
\text { d. Allergic reactions } \\
\text { e. Hyper parasympathetic regimen }\end{array}$ & $7(4.0 \%)$ \\
\hline $\begin{array}{l}\text { Disease Characteristics } \\
\text { (correct answer: False) }\end{array}$ & COPD-induced lung airflow limitation is reversible. & $59(33.3 \%)$ \\
\hline $\begin{array}{l}\text { Symptoms (correct answer: } \\
\text { True) }\end{array}$ & Symptoms of COPD include chronic cough, sputum, dyspnea, chest tightness and so on. & $17 \mid(96.6 \%)$ \\
\hline $\begin{array}{l}\text { Diagnosis (correct answer: } \\
\text { False) }\end{array}$ & $\begin{array}{l}\text { If a patient is suspected and has a FEV/FVC }<90 \% \text { from a pulmonary function test, the } \\
\text { patient is diagnosed with COPD. }\end{array}$ & $23(13.0 \%)$ \\
\hline $\begin{array}{l}\text { Guidelines (correct answer: } \\
\text { True) }\end{array}$ & The most commonly used international guideline for the treatment of COPD is GOLD. & $48(27.1 \%)$ \\
\hline $\begin{array}{l}\text { Medications (correct answer: } \\
\text { False) }\end{array}$ & $\begin{array}{l}\text { Inhaled drugs are the first choice for maintenance treatment of chronic obstructive } \\
\text { pulmonary disease, such as short-acting } \beta_{2} \text { adrenoceptor agonists (SABAs). }\end{array}$ & $17(9.6 \%)$ \\
\hline $\begin{array}{l}\text { Medications (correct answer: } \\
\text { False) }\end{array}$ & $\begin{array}{l}\text { Inhaled glucocorticoids are not commonly used in the treatment of COPD due to strong } \\
\text { adverse drug reactions. }\end{array}$ & $45(25.4 \%)$ \\
\hline $\begin{array}{l}\text { Adverse Drug Reactions } \\
\text { (correct answer: True) }\end{array}$ & $\begin{array}{l}\text { Common adverse reactions to theophylline drugs include nausea, vomiting, diarrhea, } \\
\text { food reflux, and headaches. }\end{array}$ & $14 \mid(79.7 \%)$ \\
\hline $\begin{array}{l}\text { Medications (correct answer: } \\
\text { True) }\end{array}$ & Short-acting bronchodilators commonly used during the acute exacerbation of COPD. & $132(74.6 \%)$ \\
\hline $\begin{array}{l}\text { Medications (correct answer: } \\
\text { True) }\end{array}$ & $\begin{array}{l}\text { Short-term oral glucocorticoids can be used during exacerbations, with the aim of } \\
\text { shortening the recovery time and reducing the severity of exacerbations and the risk of } \\
\text { early relapses. }\end{array}$ & $124(70.1 \%)$ \\
\hline $\begin{array}{l}\text { Non-Drug Treatments } \\
\text { (correct answer: a b c) }\end{array}$ & $\begin{array}{l}\text { Other treatments that pharmacists can use to help patients with chronic obstructive } \\
\text { pulmonary disease include: } \\
\text { a. Assisting patients to quit smoking } \\
\text { b. Recommending patients to receive flu vaccine } \\
\text { c. Encouraging patients to exercise more } \\
\text { d. Advising patients to reduce salt intake }\end{array}$ & $12(6.8 \%)$ \\
\hline $\begin{array}{l}\text { Pulmonary Rehabilitation } \\
\text { (correct answer: True) }\end{array}$ & $\begin{array}{l}\text { Pulmonary rehabilitation services for patients with COPD can improve shortness of } \\
\text { breath and exercise tolerance. }\end{array}$ & $155(87.6 \%)$ \\
\hline
\end{tabular}

COPD patients should take place at the design of bachelor education program as a priority. This should also be echoed with a more rigorous assessment of COPDrelated knowledge at the national examination of licensed pharmacists.

This study also found that CPD was significantly associated with pharmacists' overall knowledge level of COPD management. Such finding is not surprising as reviews have shown that CPD can improve knowledge, performance skills, attitudes, and behavior of pharmacists and other health professionals in a community setting. ${ }^{31-33}$ CPD on COPD for pharmacist is particularly essential for ensuring the quality of pharmaceutical care as new developments in therapeutics and changes in the COPD treatment guidelines occur over time. ${ }^{34}$ Community pharmacist, if properly trained, may provide spirometry service to identify respiratory disease abnormalities, monitor disease control and evaluate medication adherence, and 
help review of COPD pharmacotherapy based on evidence-based guidelines. ${ }^{35,36}$ For instance, a study showed that a COPD interactive training program provided to community pharmacists could improve the identification of high-risk individuals and the performance of spirometry to identify airflow obstruction. ${ }^{18}$ Unfortunately, as reflected by the knowledge gaps of the community pharmacists in this study, underutilization of spirometry in COPD diagnosis and lack of spirometry referral for highrisk patients were highly likely in the country.

At present, these shortcomings were met with multiple ground-breaking opportunities. The network of community pharmacies was fast growing. The number of community pharmacists had increased to 489,000 in 2018 from 388,000 in 2009, representing more than $26 \%$ increase over the decade. ${ }^{37}$ Of the 489,000 community pharmacies, $52.1 \%$ were chain pharmacies owned by 5671 enterprises. ${ }^{37}$ The significant portion of chain pharmacies may allow the delivery of a more structured and standardized CPD operated through the chain retail network. Moreover, according to the policy of Healthy China 2030, a high-level government commitment was set to establishing an accessible, affordable, and efficient health system for all by 2030. Among the various goals, there were actions planned precisely to COPD, such as reducing the mortality rate of chronic respiratory diseases and raising COPD awareness. ${ }^{38}$ Such recommended actions were to receive growing commitment and investment to advance public health and disease prevention. For instance, more and more COPD medications have been included in the reimbursement of the social insurance system, diverting many patients away from hospital to obtain their medications in community pharmacies. ${ }^{39}$ Moreover, the official document by the Certification Center for Licensed Pharmacist of National Medical Products Administration "Regulation of practice for licensed pharmacist" also mandated the provision of pharmaceutical care by licensed pharmacists to ensure rational use of medicines. ${ }^{29}$ Properly designed CPD is utmost important to promote the transformation of community pharmacists into a key point-of-care for COPD patients during these critical moments.

To our knowledge, this is the first study concerning community pharmacists' knowledge about COPD management in China. However, there are still some limitations to this research. First, in this study, we selected three cities in China as the survey locations. While the three cities are from different regions of China to represent the possible variation of situations for community pharmacists, future studies can re-test our research findings in other regions. Second, this study focused on community pharmacists' knowledge about COPD management and its affecting factors. Future studies can investigate the relationships between community pharmacists' knowledge and realistic practice of COPD management to design more specific interventions to promote community pharmacists' contribution to COPD patients.

\section{Conclusion}

COPD is a long-term respiratory condition that exerts a progressive impact on patients' quality of life. Community pharmacists in China are positioned to participate in integrated management to help patients prevent chronic symptoms, minimize exacerbation, maintain an acceptable level of physical activities, and avoid the need for hospitalizations. To achieve these goals, community pharmacists' sufficient knowledge about COPD is crucial to their role expansion and consolidation in COPD management. However, as shown in this study, the knowledge base of community pharmacists in China was inadequate to support their practice and weaknesses in the knowledge about the etiology, pathophysiology, pharmacotherapy, and non-pharmacotherapy were prominent. Their overall knowledge level about COPD management was significantly associated with university education level, on-the-job training, and whether selling COPD drugs at their community pharmacy. Considering a lack of knowledge and service skills inevitably affect effective provision of professional services by community pharmacists, there is any urgent need to reform and modernize the pharmacy education program and curriculum, and to offer practicing pharmacists ongoing learning opportunities to ensure the provision of professional care for COPD patients that is reliable and based on the best available evidence.

\section{Data Sharing Statement}

All the data for this study can be available from the corresponding authors (COLU) with reasonable request.

\section{Ethics Approval and Informed Consent}

The study was reviewed and approved by the Ethics Committee of China Pharmaceutical University (ndrplc201901). Informed consent is obtained from the participants. 


\section{Acknowledgments}

We acknowledge the comments from the colleagues at the University of Macau and China Pharmaceutical University.

\section{Author Contributions}

These authors contributed as co-first authorship to the paper: Yuqi $\mathrm{Hu}$ and Dongning Yao. All authors made a significant contribution to the work reported, whether that is in the conception, study design, execution, acquisition of data, analysis and interpretation, or in all these areas; took part in drafting, revising or critically reviewing the article; gave final approval of the version to be published; have agreed on the journal to which the article has been submitted; and agree to be accountable for all aspects of the work.

\section{Funding}

This work was supported by a grant from the National Licensed Pharmacist Development Research Center at the China Pharmaceutical University (under Grant No. ndrplc201901).

\section{Disclosure}

The authors declare no conflicts of interest.

\section{References}

1. World Health Organization. Chronic respiratory diseases: overview. Available from: https://www.who.int/health-topics/chronicrespiratory-diseases\#tab=tab_1. Accessed April 17, 2020.

2. World Health Organization. Chronic respiratory diseases: burden of COPD; Available from: https://www.who.int/respiratory/copd/bur den/. Accessed April 17, 2020.

3. López-Campos JL, Tan W, Soriano JB. Global burden of COPD. Respi. 2016;21(1):14-23. doi:10.1111/resp.12660

4. Berry CE, Wise RA. Mortality in COPD: causes, risk factors, and prevention. J COPD. 2010;7(5):375-382. doi:10.3109/15412555. 2010.510160

5. Soriano JB, Zielinski J, Price D. Screening for and early detection of chronic obstructive pulmonary disease. Lancet. 2009;374(9691): 721-732. doi:10.1016/S0140-6736(09)61290-3

6. Barnes P, Celli B. Systemic manifestations and comorbidities of COPD. Eur Respir J. 2009;33(5):1165-1185. doi:10.1183/09031936. 00128008

7. Ehteshami-Afshar S, FitzGerald J, Doyle-Waters M, et al. The global economic burden of asthma and chronic obstructive pulmonary disease. Int J Tuberc Lung Dis. 2016;20(1):11-23. doi:10.5588/ ijtld.15.0472

8. Mannino DM, Thorn D, Swensen A, et al. Prevalence and outcomes of diabetes, hypertension and cardiovascular disease in COPD. Eur Respir J. 2008;32(4):962-969. doi:10.1183/09031936.00012408

9. Mohan A, Chandra S, Agarwal D, et al. Prevalence of viral infection detected by PCR and RT-PCR in patients with acute exacerbation of COPD: a systematic review. Respirology. 2010;15(3):536-542. doi: $10.1111 / \mathrm{j} .1440-1843.2010 .01722 . x$

10. Ko FW, Hui DS. Air pollution and chronic obstructive pulmonary disease. Respirology. 2012;17(3):395-401. doi:10.1111/j.1440-1843. 2011.02112.x
11. Huang F, Zhao A, Chen RJ, et al. Ambient temperature and outpatient visits for acute exacerbation of chronic bronchitis in Shanghai: a time series analysis. Biomed Environ Sci. 2015;28(1):76-79.

12. Gardiner C, Gott M, Payne S, et al. Exploring the care needs of patients with advanced COPD: an overview of the literature. Respir Med. 2010;104(2):159-165. doi:10.1016/j.rmed.2009.09. 007

13. van der Molen $T$, van Boven JF, Maguire $T$, et al. Optimizing identification and management of COPD patients-reviewing the role of the community pharmacist. Br J Clin Pharm. 2017;83 (1):192-201. doi:10.1111/bcp.13087

14. Fathima M, Naik-Panvelkar P, Saini B, et al. The role of community pharmacists in screening and subsequent management of chronic respiratory diseases: a systematic review. J Oncol Pharm Pract. 2013;11(4):228.

15. Verma A, Harrison A, Torun P, et al. Are pharmacists reducing COPD'S impact through smoking cessation and assessing inhaled steroid use? Respir Med. 2012;106(2):230-234. doi:10.1016/j. rmed.2011.08.011

16. Zhong H, Ni X-J, Cui M, et al. Evaluation of pharmacist care for patients with chronic obstructive pulmonary disease: a systematic review and meta-analysis. Int J Clin Pharm. 2014;36(6):1230-1240. doi:10.1007/s11096-014-0024-9

17. Wright D, Twigg M, Thornley T. Chronic obstructive pulmonary disease case finding by community pharmacists: a potential costeffective public health intervention. Int J Pharm Pract. 2015;23 (1):83-85. doi:10.1111/ijpp.12161

18. Castillo D, Burgos F, Guayta R, et al. Airflow obstruction case finding in community-pharmacies: a novel strategy to reduce COPD underdiagnosis. Respir Med. 2015;109(4):475-482. doi:10.1016/j. rmed.2015.02.009

19. Jarab AS, AlQudah SG, Khdour M, et al. Impact of pharmaceutical care on health outcomes in patients with COPD. Int J Clin Pharm. 2012;34(1):53-62. doi:10.1007/s11096-011-9585-z

20. Wright D, Twigg M, Barton G, et al. An evaluation of a multi-site community pharmacy-based chronic obstructive pulmonary disease support service. Int J Pharm Pract. 2015;23(1):36-43. doi:10.1111/ ijpp. 12165

21. Tommelein E, Mehuys E, Van Hees T, et al. Effectiveness of pharmaceutical care for patients with chronic obstructive pulmonary disease (PHARMACOP): a randomized controlled trial. $\mathrm{Br} \mathrm{J}$ Clin Pharmacol. 2014;77(5):756-766. doi:10.1111/bcp.12242

22. International Pharmaceutical Federation (FIP). Beating non-communicable diseases in the community; 2019. Available from: https://www.fip.org/files/content/publications/2019/beatingncds-in-the-community-the-contribution-of-pharmacists.pdf. Accessed April 17, 2020.

23. Tommelein E, Tollenaere K, Mehuys E, et al. Pharmaceutical care for patients with COPD in Belgium and views on protocol implementation. Int J Clin Pharm. 2014;36(4):697-701. doi:10.10 07/s11096-014-9956-3

24. Heikkila JM, Parkkamaki S, Salimaki J, et al. Community pharmacists' knowledge of COPD, and practices and perceptions of medication counseling of COPD patients. Int J COPD. 2018;13:2065-2074. doi: $10.2147 /$ copd.S159726

25. Certification Center for Licensed Pharmacist of NMPA. Statistics of licensed pharmacist registration; 2019. Available from: http:// www.cqlp.org/info/link.aspx?id=3681\&page=1. Accessed April 17, 2020.

26. International Pharmaceutical Federation (FIP). Pharmacy workforce intelligence: global trends report; 2018. Available from: https://www. fip.org/www/streamfile.php?filename=fip/PharmacyEducation/ Workforce_Report_2018.pdf. Accessed November 23, 2020.

27. Hu M, Yee G, Zhou N, et al. Development and current status of clinical pharmacy education in China. Am J Pharm Educ. 2014;78 (8):157. doi:10.5688/ajpe788157 
28. Certification Center for Lisenced pharmacist of NMPA. Who can apply for the national qualification examination for licensed pharmacists; Available from: http://www.cqlp.org/info/link.aspx?id= 3714\&page $=1$. Accessed April 17, 2020.

29. Jiang J, Liu Y, Wang Y, et al. Clinical pharmacy education in China. Am J Pharm Educ. 2011;75(3):2. doi:10.5688/ajpe75357c

30. Liang J, Abramson MJ, George J. Educational interventions for health professionals managing COPD in primary care. Cochrane Database Syst Rev. 2017;2017(5).

31. Bloom BS. Effects of continuing medical education on improving physician clinical care and patient health: a review of systematic reviews. Int J Technol Assess Health Care. 2005;21(3):380-385. doi:10.1017/S026646230505049X

32. Robertson MK, Umble KE, Cervero RM. Impact studies in continuing education for health professions: update. J Contin Educ Health Prof. 2003;23(3):146-156. doi:10.1002/chp.1340230305

33. Global Initiative for Chronic Obstructive Pulmonary Disease. 2020 GOLD reports; 2019. Available from: https:/goldcopd.org/wpcontent/uploads/2019/12/GOLD-2020-FINAL-ver1.2-03Dec19 WMV.pdf. Accessed April 17, 2020.

34. Cawley MJ, Warning WJ. Impact of a pharmacist-driven spirometry clinic service within a community family health center: a 5-year retrospective review. J Res Pharm Pract. 2018;7(2):88. doi:10.41 03/jrpp.JRPP_17_101
35. Cawley MJ, Warning WJ. Pharmacists performing quality spirometry testing: an evidence based review. Int J Pharm Pract. 2015;37 (5):726-733

36. Ministry Of Commerce People's Republic Of China. Statistical analysis report on the operation of the pharmaceutical distribution industry; 2017. Available from: http://yplt.mofcom.gov.cn/stat/page/ auth/DrugWall.html. Accessed April 17, 2020.

37. Xinhua News Agency. Healthy China 2030 planning outline; 2016. Available from: http://www.gov.cn/xinwen/2016-10/25/content 5124174.htm. Accessed April 17, 2020.

38. National Healthcare Security Administration. Drug catalog of national basic healthcare, industrial injury insurance and maternity insurance; 2019. Available from: http://www.nhsa.gov.cn/art/2019/8/ 20/art 37_1666.html. Accessed April 17, 2020.

39. Certification Center for Lisenced pharmacist of NMPA. Business specifications of licensed pharmacist; 2016 Available from: http:// w w w . c q l p . or g/c q l pa d m in man a ge/u p files/201612/ 20161205164252986.pdf. Accessed April 17, 2020.

International Journal of Chronic Obstructive Pulmonary Disease

Dovepress

\section{Publish your work in this journal}

The International Journal of COPD is an international, peer-reviewed journal of therapeutics and pharmacology focusing on concise rapid reporting of clinical studies and reviews in COPD. Special focus is given to the pathophysiological processes underlying the disease, intervention programs, patient focused education, and self management protocols. This journal is indexed on PubMed Central, MedLine and CAS. The manuscript management system is completely online and includes a very quick and fair peer-review system, which is all easy to use. Visit http://www.dovepress.com/testimonials.php to read real quotes from published authors. 